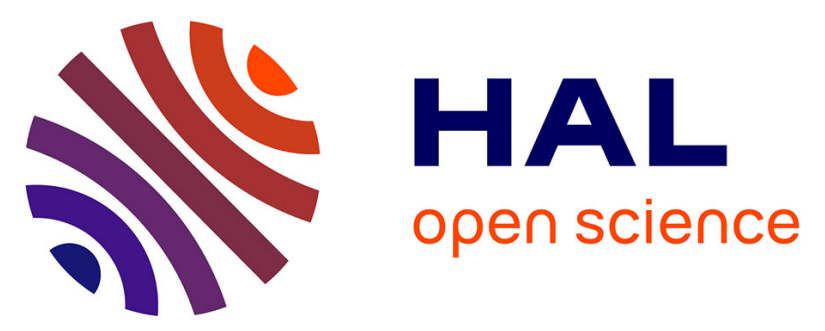

\title{
FGFR1 actionable mutations, molecular specificities, and outcome of adult midline gliomas
}

Alberto Picca, Giulia Berzero, Franck Bielle, Mehdi Touat, Julien Savatovsky, Marc Polivka, Elena Trisolini, Sheida Meunier, Yohann Schmitt, Ahmed Idbaih, et al.

\section{To cite this version:}

Alberto Picca, Giulia Berzero, Franck Bielle, Mehdi Touat, Julien Savatovsky, et al.. FGFR1 actionable mutations, molecular specificities, and outcome of adult midline gliomas. Neurology, 2018, 90 (23), pp.e2086-e2094. 10.1212/WNL.0000000000005658 • hal-01971530

\section{HAL Id: hal-01971530 \\ https://hal.sorbonne-universite.fr/hal-01971530}

Submitted on 7 Jan 2019

HAL is a multi-disciplinary open access archive for the deposit and dissemination of scientific research documents, whether they are published or not. The documents may come from teaching and research institutions in France or abroad, or from public or private research centers.
L'archive ouverte pluridisciplinaire HAL, est destinée au dépôt et à la diffusion de documents scientifiques de niveau recherche, publiés ou non, émanant des établissements d'enseignement et de recherche français ou étrangers, des laboratoires publics ou privés. 


\section{FGFR1 actionable mutations, molecular specificities, and outcome of adult midline gliomas}

Alberto Picca, MD, Giulia Berzero, MD, Franck Bielle, MD, PhD, Mehdi Touat, MD, Julien Savatovsky, MD, Marc Polivka, MD, Elena Trisolini, MSc, Sheida Meunier, BSc, Yohann Schmitt, MSc, Ahmed Idbaih, MD, PhD, Khe Hoang-Xuan, MD, PhD, Jean-Yves Delattre, MD, PhD, Karima Mokhtari, MD, Anna Luisa Di Stefano, MD, PhD, and Marc Sanson, MD, PhD

\begin{abstract}

\section{Objective}

To characterize the prevalence and prognostic significance of major driver molecular alterations in adult midline diffuse gliomas (MLG).

\section{Methods}

Adults with histologically proven MLG diagnosed between 1996 and 2017 were identified from our tumor bank, systematically reviewed, and reclassified according to WHO 2016. Targeted sequencing was performed, including determination of H3F3A, HIST1H3B, TERTp, IDH1/2, FGFR1, p16/CDKN2A, and EGFR status.
\end{abstract}

\section{Results}

A total of 116 adult patients (M/F 71/45, median age 46.5 years) with MLG (17 cerebellar, 8 spinal, 30 brainstem, 57 thalamic, and 4 diencephalic nonthalamic) were identified. Most patients had high-grade disease at presentation (grade II: 11\%, grade III: $15 \%$, grade IV: $75 \%$ ). Median overall survival was 17.3 months (14.5-23.8 months). Main molecular alterations observed were TERT promoter, H3F3A, and hotspot FGFR1 (N546 and K656) mutations, in $37 \%, 34 \%$, and $18 \%$ of patients, respectively. IDH1 mutations only affected brainstem gliomas $\left(6 / 24\right.$ vs $\left.0 / 78 ; p=7.5 \times 10^{-5}\right)$, were mostly non-R132H (contrasting with hemispheric gliomas, $p=0.0001$ ), and were associated with longer survival (54 vs 12 months). TERT promoter mutation (9.1 vs 24.2 months), CDKN2A deletion ( 9.9 vs 23.8 months), and EGFR amplification ( 4.3 vs 23.8 months) were associated with shorter survival. Of interest, in contrast with pediatric MLG, H3K27M mutations were not associated with worse prognosis (23 vs 15 months).

\section{Conclusions}

Patients with adult MLG present with unique clinical and molecular characteristics, differing from their pediatric counterparts. The identification of potentially actionable FGFR1 mutations in a subset of adult MLG highlights the importance of comprehensive genomic analysis in this rare affection.

\section{Correspondence}

Dr. Sanson

marc.sanson@aphp.fr

From Sorbonne Université (A.P., G.B., F.B., M.T., E.T., S.M., Y.S., A.I., K.H.-X., J.-Y.D., K.M., A.L.D.S., M.S.), UPMC Univ Paris 06 UMR S 1127 , Inserm U 1127, CNRS UMR 7225, ICM; Service de Neurologie 2 (A.P., G.B., M.T., A.I., K.H.-X., J.-Y.D., M.S.) and Laboratoire R Escourolle 2 (F.B., K.M.), AP-HP, Hôpital de la Pitié-Salpêtrière, Paris, France; Neuroscience Consortium (A.P., G.B.), Monza Policlinico and Pavia Mondino, University of Pavia, Italy; Centre d'Imagerie (J.S.), Fondation A de Rothschild; Laboratoire d'Anatomie Pathologique (M.P.), AP-HP, Hôpital Lariboisière, Paris, France; Pathology Unit (E.T.), AOU “Maggiore della Carità" di Novara, Italy; Onconeurotek Tumour Bank (J.-Y.D., K.M., M.S.), GH Pitié-Salpêtrière; and Department of Neurology (A.L.D.S.), Foch Hospital, Suresnes, Paris, France. 


\section{Glossary}

$\mathbf{C I}=$ confidence interval $\mathbf{M L G}=$ midline gliomas; $\mathbf{O S}=$ overall survival .

Diffuse midline gliomas (MLG) are rare entities occurring predominantly in children and young adults. ${ }^{1}$ Genomic studies in pediatric MLG showed that these tumors frequently harbor recurrent $\mathrm{K} 27 \mathrm{M}$ missense mutations in $\mathrm{H} 3 \mathrm{~F} 3 \mathrm{~A}$ and HIST1H3B genes, which both encode variants of the histone $\mathrm{H} 3$ protein. ${ }^{2-4}$ While HIST1H3B mutations are anatomically restricted to brainstem, ${ }^{4,5} \mathrm{H} 3 \mathrm{~F} 3 \mathrm{~A}$ mutants have been reported in MLG of various locations. ${ }^{2,5-8}$ In pediatric MLG, these mutations associate with more aggressive clinical phenotype and poorer prognosis. ${ }^{6,89}$ Based on these observations, the WHO 2016 classification introduced "diffuse midline glioma, H3K27M-mutant" as a new grade IV entity, even in the absence of histopathologic markers of anaplasia. ${ }^{10}$

In adults, fewer than $10 \%$ of diffuse gliomas arise in midline structures. ${ }^{1,11}$ Recent works suggested that they may differ from both pediatric MLG and adult supratentorial gliomas. As an illustration, although $H 3 F 3 A$ mutations have been reported in adult MLG, ${ }^{7,12-15}$ their prognostic significance in adults remains unclear. ${ }^{12,13}$ While less frequent, actionable ${ }^{16,17}$ IDH1 and FGFR 1 hotspot mutations have been described in this population. ${ }^{18,19}$

Overall, the genomic landscape of adult MLG remains poorly understood. Indeed, the need for histologic confirmation in presence of a typical radiologic presentation is debated, because of the surgical risks and assumption of limited benefit on overall survival (OS). ${ }^{20}$

We assumed that unravelling the genomic landscape of these tumors will enable better defining the prognostic value of molecular biomarkers in this disease and identify new therapeutic strategies. In this study, we report the clinical, histologic, and molecular characteristics of 116 adult patients with MLG, and assess the prevalence and prognostic significance of major driver molecular alterations.

\section{Methods}

\section{Patients and tumor samples}

Patients ( $\geq 15$ years) with diagnosis of MLG were retrospectively identified from our database (OncoNeuroTek, GH Pitié-Salpêtrière, Paris, 1996-2017) according to the following criteria: 1) tumor arising in midbrain location (thalamus, hypothalamus, pineal region, brainstem, cerebellum, or spinal cord), verified on neuroimaging at diagnosis; 2) histopathologic confirmation of diffuse glioma according to WHO 2016 classification; and 3) available follow-up data.

All tumor samples underwent histopathologic review (F.B. and K.M.) and, if required, additional diagnostic immunohistochemical stainings were performed.
Radiologic analysis was performed by A.P. and J.S. and scored contrast enhancement (absent, mild/moderate, marked/ avid) and radiologic necrosis (none, $<5 \%, 6 \%-33 \%$, $34 \%-67 \%,>67 \%$ of the bulk), according to Visually Accessible Rembrandt Images (VASARI) criteria. $^{21}$

As a control, we used a set of hemispheric diffuse gliomas with available tumor DNA.

\section{Standard protocol approvals, registrations, and patient consents}

All tumor samples and clinical data were collected with written informed consent in accordance with the tenets of the Declaration of Helsinki.

\section{DNA extraction}

DNA was extracted from formalin-fixed paraffin-embedded or frozen samples, as previously described. ${ }^{15}$

\section{Sanger sequencing}

Genes were sequenced using the Sanger method for the codons 132 of IDH1, 172 of IDH2, 27 of H3F3A, 27 of HIST1H3B, 546 and 656 of FGR1, 600 of BRAF and TERT promoter at position -250 and -228 after standard PCR amplification, as previously described. ${ }^{15,22}$

The primers used were as follows: for IDH1, F-TGTGTTGA GATGGACGCCTATTTG, R-TGCCACCAACGACCAA GTCA; for IDH2, F-5-GC CCGGTCTGCCACAAAGTC, R-5-TTGGCAGACTCCAGAGCCCA; for H3F3A, F-GTG ATCGTGGCAGGAAAAGT, R-CAAGAGAGACTTTGT CCCATTTT; for HIST1H3B, F-GTTTTGCCATGGCT CGTACT, R-AAGCGAAGATCGGTCTTGAA; for TERT promoter region, F- GGCCGATTCGACCTCTCT, R-AGC ACCTCGCGGTAGTGG; for FGFR1, F-CCTCCTCCC TTCCCAAGTAA, R-GGACTGATACCCCAGCTCAG; for codon 546 hotspot (exon 12), F-CTTCCAGCTCCCTCACC TC, R-CCCACTCCTTGCTTCTCAGAT for codon 656 hotspot (exon 14); and for BRAF codon 600, F-TGC TTGCTCTGATAGGAAAATG, R-CAGGATCTCAGGGCCAAAAAT.

\section{Array comparative genomic hybridization}

When enough material was available, array comparative genomic hybridization analysis was performed as previously described, ${ }^{23}$ to determine EGFR amplification, $p 16 / C D K N 2 A$ deletion, and chromosomes 1p, 19q, 9p, 10p, and 10q losses.

\section{MGMT methylation}

DNA methylation status of the MGMT promoter was determined by bisulfite conversion and subsequent nested methylation-specific PCR, a 2-stage PCR approach. 


\section{Immunohistochemical analyses}

Detection of IDH1 R132H mutant enzyme, Ki67, and ATRX nuclear expression were performed as previously described. ${ }^{24,25}$ In particular, the loss of nuclear ATRX expression was considered specific when tumor cell nuclei were unstained while the nuclei of non-neoplastic cells were ATRX-positive. Antibody antihistone H3.3 K27M mutant (ABE419; Millipore, Burlington, MA) was used at dilution 1/1,000. Samples were considered histone H3 K27M or IDH1 R132H mutated when immunohistochemistry was positive for the presence of the altered protein. $^{26,27}$

\section{Statistical analysis}

OS was defined as the time between diagnosis and death. Patients who were still alive at the last follow-up were censored for the analysis. Survival curves were calculated using the Kaplan-Meier method. Statistically significant differences between survival were assessed using the log-rank test. A log-rank test $p$ value $\leq 0.05$ (2-sided) was considered to be statistically significant. Cox model was used to evaluate the effect of quantitative variables on survival and for multivariate survival analysis. $\chi^{2}$ and Fisher exact test were used to compare qualitative variables, with $p<0.05$ considered as significant. Hierarchical clustering and multidimensional representations were used using the Ward method. The analyses were performed using R software packages.

\section{Data availability}

The complete individual data and supplementary material are available at doi: $10.5281 /$ zenodo. 1183373 .

\section{Results}

\section{Clinical and histologic features of adult MLG}

We identified 116 patients (M/F 71/45; median age 46.5 years, range 15-75) fulfilling the inclusion criteria, out of 2,649 patients with diffuse glioma of any location from our database (4.4\%), and harboring cerebellar (17), spinal (8), brainstem (30), thalamic (57), and diencephalic nonthalamic (4) midline gliomas (table e-1, links.lww.com/ $\mathrm{WNL} / \mathrm{A} 511$; figure 1). All the cases have been reviewed by a neuropathologist (F.B.) according to the 2016 WHO classification (table e-1). The predominant histologic aspect was astrocytic diffuse gliomas, but other patterns were also observed: oligodendroglial, piloid, pseudo-ependymal, pleomorphic xanthoastrocytoma-like, or embryonal tumorlike. A total of $84 / 109$ (77\%) patients had a biopsy only; 25 (23\%) had partial or subtotal surgical resection. Sixty-eight percent $(68 / 101)$ of patients received combined chemoradiation with temozolomide as first-line therapy, $17 \%$ received chemotherapy, and $12 \%$ received radiation therapy alone. Four patients did not receive any adjuvant treatment after initial diagnosis.

Figure 1 Inclusion flowchart

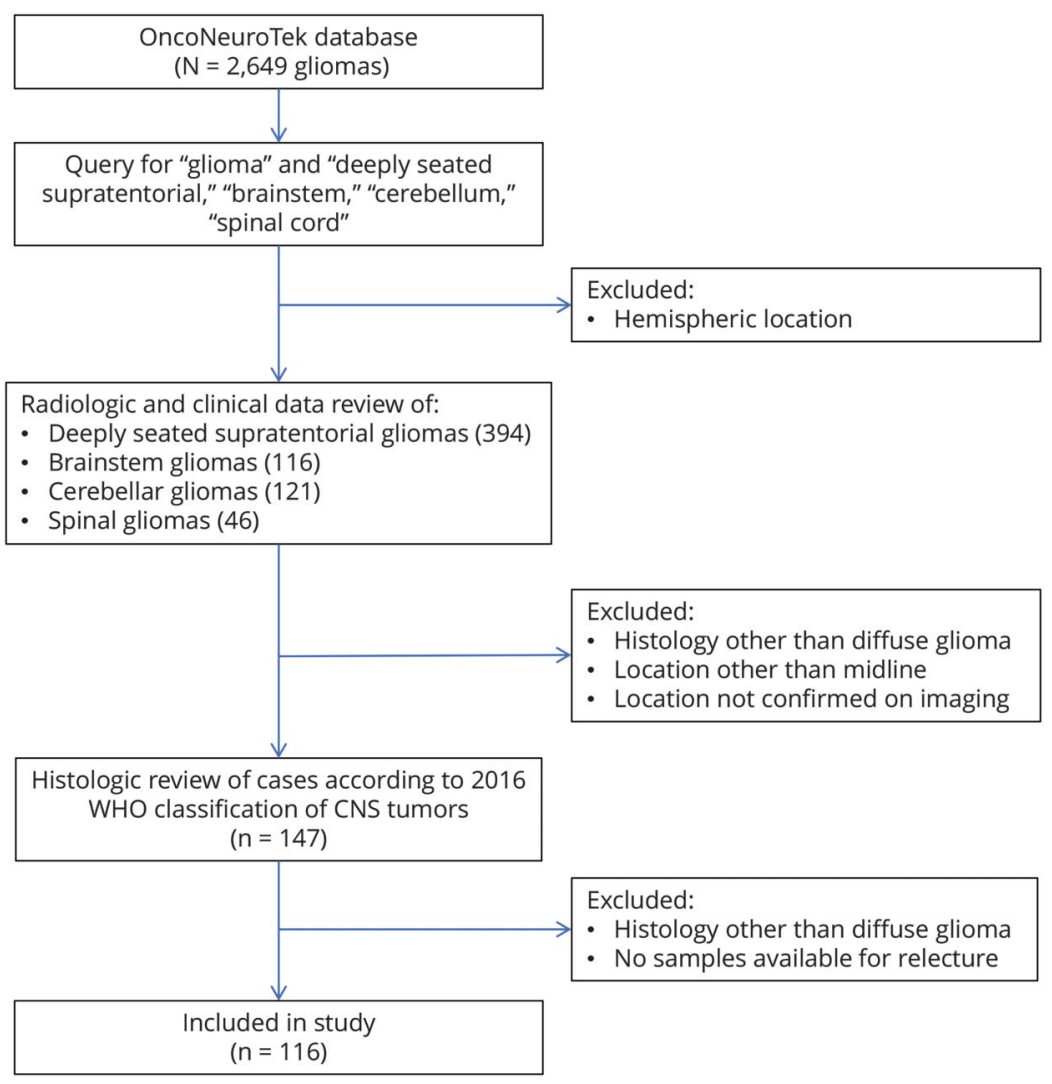




\section{Molecular characterization of adult MLG reveals the presence of recurrent hotspot mutations in FGFR1}

The frequency and type of the main molecular alterations is detailed in figure 2 . As diagnosis was based on tumor biopsy in most of the patients and tissue availability was limited, molecular analyses were focused on the alterations hypothesized to be the most relevant to the disease. Comparative genomic hybridization array could be performed in 56 cases.

Histone H3K27M mutations were found in $38 / 110$ patients (34\%) and were associated with a younger age at diagnosis (median 33 years vs 53 years, $p=6 \times 10^{-5}$, figure e-1e, links. lww.com/WNL/A510). Histone $\mathrm{H} 3$ mutations were mutually exclusive with $I D H 1$, and inversely associated with TERTp mutation, $p 16 / C D K N 2 A$ loss, and EGFR amplification (table e-1, links.lww.com/WNL/A511). H3K27M was found in all the locations but was associated with thalamic and spinal locations (table 1).

IDH1 mutations were found in 6 patients ( 1 grade II, 4 grade III, 1 grade IV) out of 102: strikingly, all 6 IDH1 mutated tumors were located in brainstem (6/24 vs 0/78 for MLG not involving the brainstem; $\left.p=7 \cdot 5 \cdot 10^{-5}\right)$. Only 1 out of the 5 IDH1 mutations identified by sequencing was IDH1 R132H; the other mutations were p.Arg132Gly (R132G) (2), p. Arg132Cys (R132C), andp.Arg132Leu (R132L), which contrasted with non-midline IDH1-mutant gliomas: we compared these results to the data from non-midline gliomas recorded in our tumor base (OncoNeuroTek) and found a difference in the pattern of IDH1 mutations between midline and non-midline gliomas $(p=0.0001)$ : out of 2,234 IDH1 mutated supratentorial gliomas, 2,083 (93.2\%) were R132H,
55 (2.5\%) were R132G, 54 (2.4\%) were R132C, 27 (1.2\%) were R132S, and 15 (0.7\%) were R132L. These data indicate that $I D H$-mutated brainstem gliomas differ from supratentorial IDH-mutated gliomas, and that immunohistochemistry anti-IDH1R132H is not the valid method for IDH screening in these tumors.

Fifty-nine patients were found IDH wild-type and K27 wildtype: this group - IDHwt-K27wt-of MLG had more frequent TERTp mutation $\left(24 / 48, p<1 \times 10^{-5}\right)$, CDKN2A deletion $(7 / 24, p=0.028)$, and EGFR amplification $(5 / 24, p=0.016)$ (figure 2). No patient had BRAF V600 mutation (0/69).

Recurrent FGFR1 mutations affecting 2 hotspots were identified in $18 \%$ of patients (13/73): p.Asn546Lys (9), p. Asn546Asp (2), and p.Lys656Glu (2) with diverse locations: $7 / 37$ thalamus (19\%), $2 / 12$ brainstem $(17 \%), 2 / 13$ cerebellar $(15 \%)$, and $1 / 3$ spinal cord $(33 \%)(p=0.9)$, in both $\mathrm{K} 27 \mathrm{M}$ MLG (6/23) and K27wt MLG (6/45), $p=0.3$; and 6/41 IDH wild-type vs $0 / 4 \mathrm{IDH}$ mutated, $p=1$ (figure 2 ). In order to investigate whether FGFR1 mutations were specific to midline located diffuse gliomas, we sequenced from our OncoNeuroTek tumor bank 479 DNA samples extracted from hemispheric gliomas (170 GBM, 151 grade III, 157 grade II, of which 197 were IDH mutated, $212 \mathrm{IDH}$ wild-type, and 70 undetermined) for the presence of FGFR1 mutations: we found only one mutation in a patient with an IDH wild-type GBM involving the corpus callosum, suggesting that FGFR1 mutations are restricted to midline diffuse gliomas (13/73 vs $\left.1 / 479 ; p=1 \cdot 2 \cdot 10^{-10}\right)$. Our data were further confirmed by public data (cbioportal.org): out of 1,722 patients with diffuse gliomas, only 2 patients had FGFR1 activating mutation $\left(13 / 73\right.$ vs $\left.2 / 1,722 ; p=10^{-16}\right)$ : 1 GBM with $\mathrm{K} 656 \mathrm{E}$

Figure 2 Age, tumor location, tumor grade, and molecular alterations of 116 patients with midline gliomas

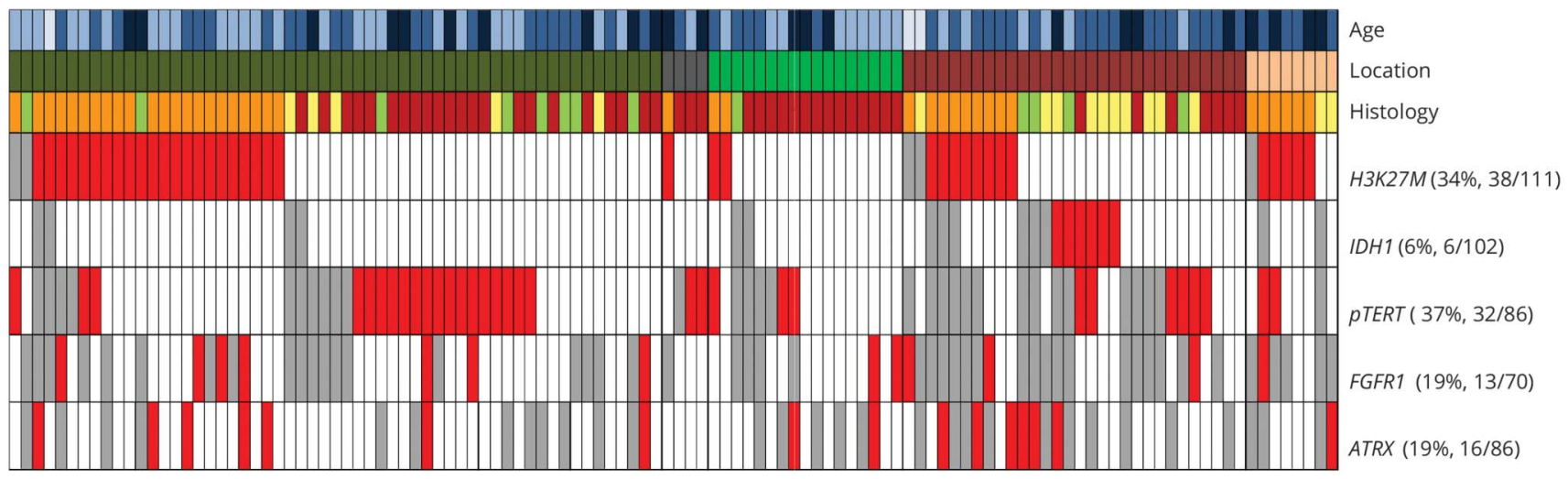

\begin{tabular}{|c|c|c|c|}
\hline Age at diagnosis & Location & Histology & Genetic alteration \\
\hline$<20$ years & Thalamus & Grade II glioma & Mutated \\
\hline $20-39$ years & Diencephalon nonthalamic & Grade III glioma & Wild-type \\
\hline 40-59 years & Cerebellum & Glioblastoma & Not available \\
\hline$\geq 60$ & Brainstem & K27 mutated diffuse glioma & \\
\hline & Spinal cord & & \\
\hline
\end{tabular}


Table 1 Clinical, histologic, and molecular characteristics in patients with H3K27M mutation vs H3K27 wildtype midline gliomas (MLG)

\begin{tabular}{|c|c|c|c|}
\hline & $\begin{array}{l}\text { K27M } \\
\text { wild-type }\end{array}$ & $\begin{array}{l}\text { K27M } \\
\text { mutated }\end{array}$ & $p$ Value \\
\hline $\mathbf{N}$ & 73 & 38 & NA \\
\hline Sex ratio (M/F) & $1.52(44 / 29)$ & $1.53(23 / 15)$ & 0.98 \\
\hline $\begin{array}{l}\text { Age at surgery, } y, \\
\text { median (range) }\end{array}$ & $53(23-75)$ & $33(15-65)$ & $<0.0001$ \\
\hline Location, \% (n) & & & 0.04 \\
\hline $\begin{array}{l}\text { Nonthalamic } \\
\text { diencephalic }\end{array}$ & $4(3 / 73)$ & $3(1 / 38)$ & \\
\hline Thalamic & $45(33 / 73)$ & $58(22 / 38)$ & \\
\hline Brainstem & $27(20 / 73)$ & $21(8 / 38)$ & \\
\hline Cerebellar & $21(15 / 73)$ & $5(2 / 38)$ & \\
\hline Spinal cord & $3(2 / 73)$ & $13(5 / 38)$ & \\
\hline $\begin{array}{l}\text { Contrast } \\
\text { enhancement, \% (n) }\end{array}$ & $72(34 / 47)$ & $88(21 / 24)$ & 0.16 \\
\hline \multicolumn{4}{|l|}{$\begin{array}{l}\text { First-line treatment, } \\
\%(n)\end{array}$} \\
\hline Surgery + RT & $14(9 / 63)$ & $9(3 / 34)$ & \\
\hline Surgery + CHT & $19(12 / 63)$ & $15(5 / 34)$ & \\
\hline Surgery + RT-CHT & $63(40 / 63)$ & $74(25 / 34)$ & \\
\hline Surgery only & $3(2 / 63)$ & $3(1 / 34)$ & \\
\hline $\begin{array}{l}\text { Median OS, } \\
\text { mo }(95 \% \mathrm{Cl})\end{array}$ & $\begin{array}{l}15.0 \text { months } \\
\text { (10.4-19.7 } \\
\text { months) }\end{array}$ & $\begin{array}{l}18.6 \text { months } \\
\text { (14.7-33.6 } \\
\text { months) }\end{array}$ & 0.65 \\
\hline $\begin{array}{l}\text { IDH mutation, } \\
\%(n)\end{array}$ & $17(5 / 30)$ & $0(0 / 14)$ & 0.16 \\
\hline ATRX loss, \% (n) & $15(8 / 54)$ & $26(8 / 31)$ & 0.25 \\
\hline $\begin{array}{l}\text { PTERT mutation, } \\
\%(n)\end{array}$ & $52(27 / 52)$ & $19(5 / 27)$ & 0.007 \\
\hline C228T & 20 & 4 & \\
\hline C250T & 7 & 1 & \\
\hline $\begin{array}{l}\text { MGMT methylation, } \\
\%(n)\end{array}$ & $38(3 / 8)$ & $0(0 / 5)$ & 0.23 \\
\hline $\begin{array}{l}\text { FGFR1 mutation, } \\
\%(\mathrm{n})\end{array}$ & $13(6 / 46)$ & $26(6 / 23)$ & 0.19 \\
\hline $\begin{array}{l}\text { EGFR amplification, } \\
\%(n)\end{array}$ & $23(7 / 31)$ & $0(0 / 22)$ & 0.03 \\
\hline P16 loss, \% (n) & $32(10 / 31)$ & $5(1 / 22)$ & 0.02 \\
\hline $\begin{array}{l}\text { BRAF mutation, } \\
\%(n)\end{array}$ & $0(0 / 43)$ & $0(0 / 24)$ & NA \\
\hline
\end{tabular}

Abbreviations: $\mathrm{CHT}=$ chemotherapy; $\mathrm{Cl}$ = confidence interval; OS = overall survival; RT = radiotherapy.

mutation but no clinical information on location ${ }^{28}$ and $11 \mathrm{p} /$ 19q-codeleted IDH1 mutantfrontal oligodendroglioma with N546K mutation. ${ }^{29}$
Figure 3 Correlation matrix of the major variables

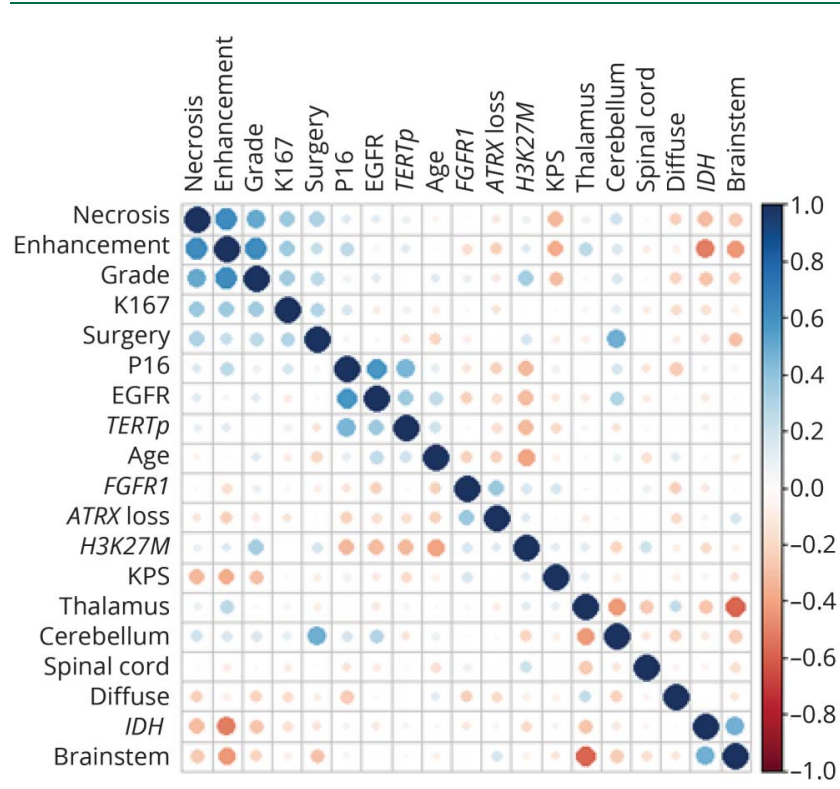

The variables are indicated in blue when associated, in purple when inversely associated. Circle diameter reflects the strength of the correlation ( $r$ value). $\mathrm{KPS}=$ Karnofsky performance status.

We then performed a hierarchical clustering on the clinical, histologic, radiologic, and molecular alterations (figure e-2, links. lww.com/WNL/A510). This table shows that IDH1 mutations cluster with the brainstem location, and FGFR1 mutations cluster with extinction of ATRX expression $(p=0.02)$, while CDKN2A loss clusters with EGFR $(p=0.0004)$ and TERTp $(p=0.01)$ mutations. Grade, radiologic necrosis, and contrast enhancement clustered together. All the variables are reported in a correlation matrix (figure 3 ) showing the positive (blue) and negative (red) associations. FGFR1 mutations tended to be associated with younger age $(p=0.06)$, as ATRX loss $(p=0.05)$, while TERTp mutation $(p=0.1)$ and EGFR amplification $(p=$ 0.05 ) tended to be associated with older age.

\section{Survival analysis}

OS was 17.3 months (95\% confidence interval [CI] 14.7-23.0 months) for the whole group, 17.3 months (95\% CI 14.5-27.5 months) for the thalamic gliomas, 16.3 months (95\% CI 11.6-52.2 months) for brainstem, 19.7 months (95\% CI 8.3-NA months) for cerebellar, and 23.0 months (95\% CI 9.3-NA months) for spinal gliomas. Out of the main clinical prognostic factors validated in gliomas, ${ }^{30-32}$ only poor Karnofsky performance status $(p=0.0007)$, high tumor grade $(p=0.01), \%$ of Ki67 labeling $(p=0.003)$, and presence of contrast enhancement $(p=0.007)$, but not age $(p=0.11)$, were associated with poor survival.

According to the $2016 \mathrm{WHO}$ classification, all K27M-mutated diffuse MLG were considered as grade IV tumors. However, the presence of histone H3K27M mutation did not correlate with a worse prognosis in our patients (table 2, figure 4A): 23 (95\% CI 16.4-45.0) vs 15 months (95\% CI 11.3-21.3), $p=0.7$. 
Table 2 Median survival according to the main genetic alterations, with log-rank test $p$ value (2-sided)

\begin{tabular}{llll}
\hline Genetic alteration & $\begin{array}{l}\text { Median OS } \\
\text { (95\% CI), } \\
\text { mo, alteration } \\
\text { present }\end{array}$ & $\begin{array}{l}\text { Median OS } \\
\text { (95\% CI), } \\
\text { mo, alteration } \\
\text { absent }\end{array}$ & $\begin{array}{l}\boldsymbol{p} \\
\text { Value }\end{array}$ \\
\hline H3K27M mutation & $23(16.4-45.0)$ & $15(11.3-21.3)$ & 0.7 \\
\hline FGFR1 mutation & $45(14.5-N A)$ & $13.8(8.3-18.6)$ & 0.01 \\
\hline TERTp mutation & $9.1(5.7-14.8)$ & $24.2(18.6-45.0)$ & $<0.0001$ \\
\hline $\begin{array}{l}\text { p16/CDKN2A } \\
\text { deletion }\end{array}$ & $9.9(4.3-N A)$ & $23.8(16.9-46.1)$ & 0.0001 \\
\hline $\begin{array}{l}\text { EGFR amplification } \\
\text { IDH1 mutation }\end{array}$ & $4.3(1.3-\mathrm{NA})$ & $23.8(16.2-40.4)$ & $<0.0001$ \\
\hline $\begin{array}{l}\text { ATRX loss } \\
54.1(51.3-N A)\end{array}$ & $15.9(12.2-19.3)$ & 0.05 \\
\hline $\begin{array}{l}\text { Loss of } \\
\text { chromosome 10p }\end{array}$ & $9.15(2.0-\mathrm{NA})$ & $32.0(18.6-54.1)$ & 0.016 \\
\hline $\begin{array}{l}\text { Loss of } \\
\text { chromosome 10q }\end{array}$ & $9.8(3.8-\mathrm{NA})$ & $29.2(18.0-52.2)$ & $<0.0001$ \\
\hline $\begin{array}{l}\text { Loss of } \\
\text { chromosome 9p }\end{array}$ & $14.8(9.1-\mathrm{NA})$ & $32.0(18.5-53.5)$ & 0.03 \\
\hline
\end{tabular}

Abbreviations: $\mathrm{Cl}$ = confidence interval; OS = overall survival.

We therefore investigated whether grading, according to the WHO 2007 classification, had a prognostic relevance in $\mathrm{H} 3 \mathrm{~K} 27 \mathrm{M}$ mutant gliomas and found no difference of survival between WHO 2007 grade II to grade IV tumors, suggesting that histone $\mathrm{H} 3$ mutant MLG represents a separated entity in adult patients (figure e-3a, links.lww.com/WNL/A510). We hypothesized that prognostic effect of histone H3K27M could have been masked by the association with younger age, which is a favorable prognostic factor. We therefore entered the 2 variables in a Cox model: however, neither $\operatorname{K27M}(p=0.2)$ nor age $(p=0.07)$ was associated with poor survival.

Finally, by stratifying for single locations, we found that K27M mutations were associated with longer OS in thalamic MLG as compared to wild-type tumors: 29.2 (95\% CI 24.2-NA) vs 14.4 months (95\% CI 9.5-33.6), $p=0.04$ (figure e-3b, links.lww.com/ WNL/A510). In brainstem tumors, after exclusion of IDH1mutated cases, we observed a similar trend: 16.4 (9.8-NA) vs 9.1 months $(0.2-13), p=0.24$. These data together suggest that $\mathrm{K} 27 \mathrm{M}$ mutation in adults is not associated with poorer outcome, showing a different effect on survival compared to what is observed in the pediatric populations so far.

IDH1 mutation, loss of ATRX, and FGFR1 mutations were associated with longer survival (table 2 and figures 4, B and D, and e-4a, links.lww.com/WNL/A510). As the IDH1 mutation was present only in brainstem gliomas, we considered only this group and found it associated with a much longer OS: 54.1 (51.3-NA) vs 11.9 months (9.1-19.3), $p=0.03$ (figure e-5a). None of the IDH1 mutant brainstem MLG showed contrast enhancement $(0 / 5)$ vs $6 / 10$ in IDH1 wild-type MLG $(p<0.05)$ (figure e-5, b-d).

IDH wild-type-K27 wild-type patients showed the worst outcome (figure 4C). This group had frequent TERTp mutation, $C D K N 2 A$ deletion, and EGFR amplification, all associated with shorter survival (table 2 and figure e-4, b-d, links.lww.com/ WNL/A510). Loss of chromosomes $10 \mathrm{q}$ and $9 \mathrm{p}$ were also associated with poorer outcome (table 2 and figure $e-4$, e and f).

Finally, to identify independent prognostic factors, we performed multivariate survival analysis. Due to missing data, we limited the Cox model analysis to the most relevant (based on our data or current knowledge) and most documented measures: age, grade, K27M, TERTp, IDH, and FGFR1 status: only TERTp, IDH, and FGFR1 status were independent prognostic markers (table 3 ).

\section{Discussion}

This retrospective study shows that adult MLG constitute a heterogeneous group with mostly high-grade neoplasms and clinical and histomolecular characteristics differing from both pediatric MLG and adult supratentorial high-grade gliomas. We identified 2 main subgroups based on the presence of histone $\mathrm{H} 3$ or IDH1 mutations, and identified hotspot FGFR1 mutations as the main potential target in this population.

The most prominent molecular subgroup consisted of histone H3 mutant MLG, in line with previous studies showing a strong association between histone $\mathrm{H} 3$ mutations and gliomagenesis of midline tumors. ${ }^{2-6,8,12-15,18,33}$ However, we observed a lower prevalence of histone $\mathrm{H} 3$ mutations compared to pediatric highgrade thalamic and brainstem gliomas $(70 \%-80 \%){ }^{2,4-6}$ In addition, clinical and molecular characteristics of patients from our cohort with histone $\mathrm{H} 3$ mutant MLG differed from pediatric patients. ${ }^{2,4,6,33}$ First, although histone $\mathrm{H} 3$ mutations were associated with younger age at diagnosis (median 33 years vs 53 years, $p=6 \times 10^{-5}$ ), we found $\mathrm{H} 3$ mutation in patients over 60 years, indicating that screening for histone $\mathrm{H} 3$ mutants should be considered in all MLG cases, regardless of age. Moreover, in contrast to pediatric gliomas, we found that histone $\mathrm{H} 3$ mutations were not associated with a worse prognosis compared to the other IDH wild-type gliomas ${ }^{12,14}$ : in the largest group, i.e., the thalamic MLG, H3 mutations were even associated with better outcome. While H3 G34 and to a lesser extent K27 mutations have been associated with alternative lengthening of telomeres in pediatric tumors, as reflected by frequent ATRX inactivation, ${ }^{3,6,8,12,34}$ we also found $\mathrm{H} 3$ mutation associated with TERTp mutation in 5 patients. Interestingly, either ATRX loss or TERTp mutation tended to be associated with poorer outcome in the subset of $\mathrm{H} 3$ mutated gliomas (OS 9.8 vs 24.2 months; $p=0.08$; data not shown).

The other main driver of alteration is $I D H$ mutation, which occurs specifically in brainstem $(6 / 24$ vs $0 / 78$ in other midline 

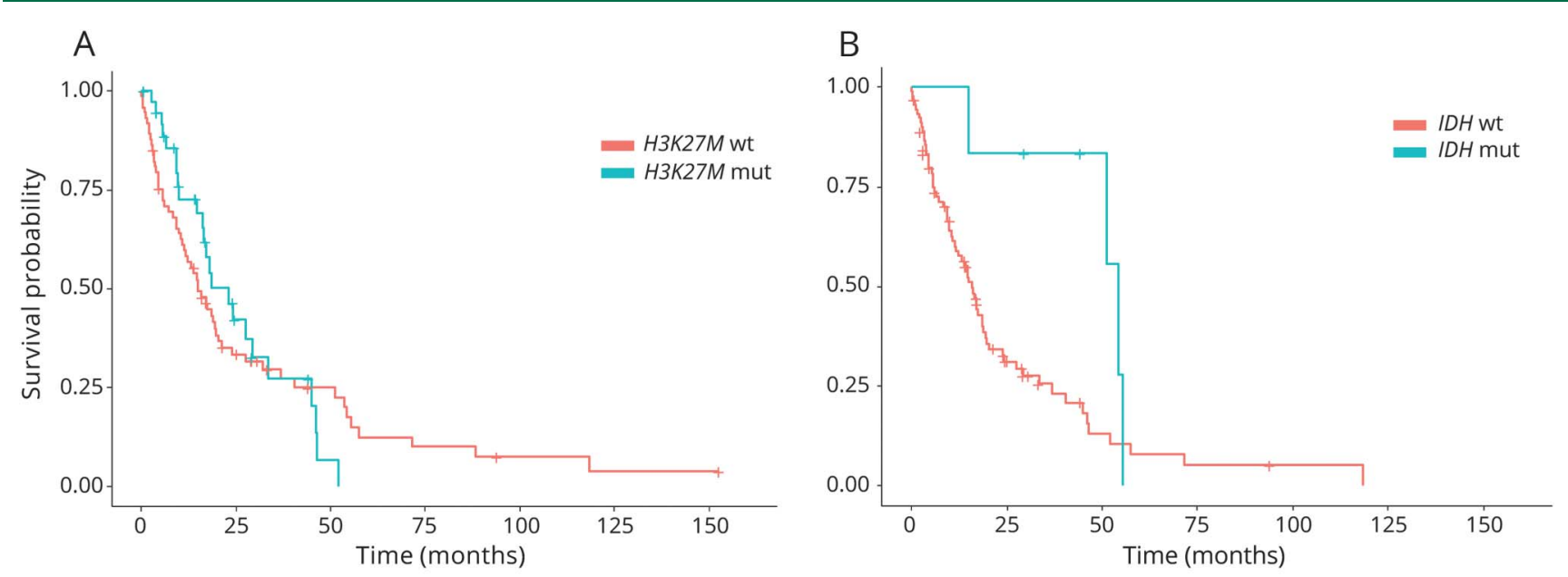

\begin{tabular}{lclllll}
\multicolumn{2}{l}{ Number at risk } \\
$-\quad 73$ & 20 & 10 & 4 & 2 & 1 & 1 \\
$-\quad 38$ & 9 & 1 & 0 & 0 & 0 & 0
\end{tabular}

\begin{tabular}{|c|c|c|c|c|c|c|}
\hline \multicolumn{7}{|c|}{ Number at risk } \\
\hline - $\quad 91$ & 19 & 5 & 2 & 1 & 0 & 0 \\
\hline 6 & 5 & 3 & 0 & 0 & 0 & 0 \\
\hline
\end{tabular}

\section{C}

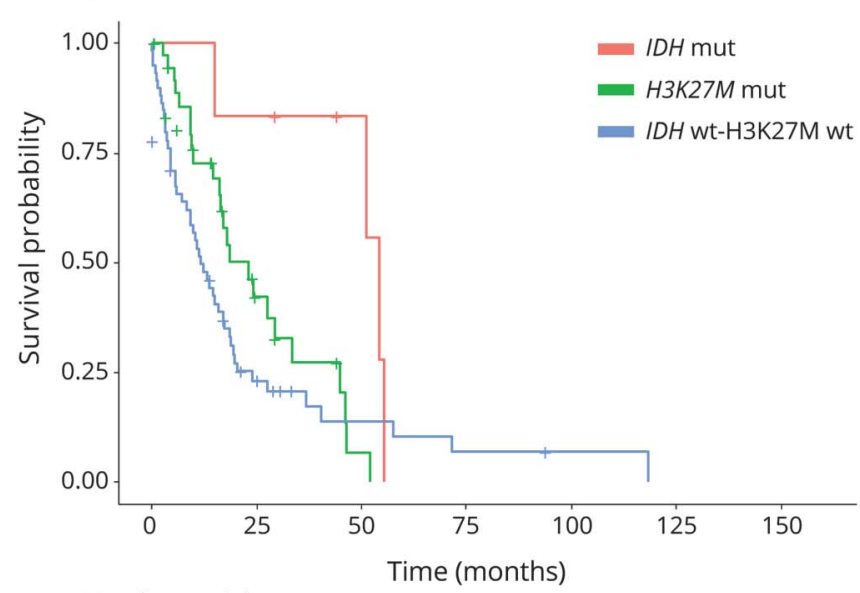

\begin{tabular}{|c|c|c|c|c|c|c|c|}
\hline \multicolumn{8}{|c|}{ Number at risk } \\
\hline - & 6 & 5 & 3 & 0 & 0 & 0 & 0 \\
\hline$=$ & 38 & 9 & 1 & 0 & 0 & 0 & 0 \\
\hline - & 59 & 11 & 4 & 2 & 1 & 0 & 0 \\
\hline
\end{tabular}

\section{D}

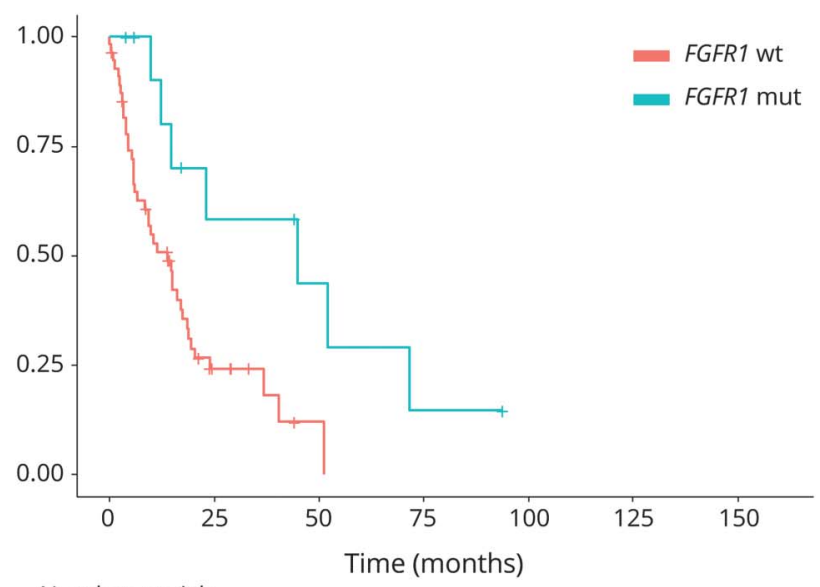

Number at risk

$\begin{array}{rrrrrrr}-56 & 8 & 1 & 0 & 0 & 0 & 0 \\ -\quad 12 & 5 & 3 & 1 & 0 & 0 & 0\end{array}$

(A) Kaplan-Meier survival curves by H3K27M status(black = wild-type, blue = mutated). Median survival for mutated patients (blue): 23 months ( $95 \%$ confidence interval [CI] 16.4-45.0 months) vs median survival for wild-type patients (black): 15 months (95\% Cl 11.3-21.3 months), $p=0.7$. Vertical bars indicate censored events. (B) Kaplan-Meier survival curves by IDH status (black = wild-type, red = mutated). Median survival for mutated patients (red): 54.1 months (95\% CI 51.3-NA months) vs median survival for wild-type patients (black): 15.9 months ( $95 \% \mathrm{Cl} 12.2-19.3$ months), $p=0.05$. Vertical bars indicate censored events. (C) Kaplan-Meier survival curves by H3K27M and IDH status (black = both wild-type, blue $=\mathrm{H} 3 \mathrm{~K} 27 \mathrm{M}$ mutated, red $=$ IDH mutated). Median survival for H3K27M mutated patients (blue): 23.0 months (95\% Cl 16.4-45.0 months) vs median survival for IDH mutated patients (red): 54.1 months (95\% CI 51.3-NA months) vs median survival for wild-type patients (black): 11.6 months ( $95 \%$ Cl 9.1-18.5 months), $p=0.05$. Vertical bars indicate censored events. (D) Kaplan-Meier survival curves by FGFR1 status (black = wild-type, red = mutated). Median survival for mutated patients (red): 45 months (95\% CI 14.5-NA months) vs median survival for wild-type patients (black): 13.8 months ( $95 \% \mathrm{Cl} 8.3-18.6$ months), $p=0.01$. Vertical bars indicate censored events.

localizations). The majority of IDH1 mutations in this cohort were non- $\mathrm{R} 132 \mathrm{H}$, indicating that the widely used anti-R132H immunohistochemistry is not appropriate in brainstem gliomas and has probably underestimated the proportion of IDH1mutant tumors. $^{35}$ Systematic IDH1 sequencing should be performed whenever feasible in brainstem gliomas. Indeed, as observed in hemispheric gliomas, IDH1 mutation is associated with better outcome (OS 54.1 vs 15.9 months in our cohort), and may in part explain why adults with brainstem gliomas have better survival than children. ${ }^{19,35,36}$ In addition to its prognostic value, the recognition of $I D H 1$ mutations may open therapeutic opportunities, as inhibitors of IDH1-mutant enzymes have demonstrated antitumor potential and entered clinical trials for patients with $I D H 1$ mutations. ${ }^{37}$

In addition to $I D H 1$ mutation, we identified other potentially targetable hotspot mutations affecting N546 and K656 residues of FGFR1 in $19 \%$ of our patients. In contrast to IDH1 mutation, FGFR1 mutations were not associated with any specific location or any molecular subgroup. Somatic FGFR1 
Table 3 Cox model analysis (due to missing data, we limited the analysis to the most relevant and most documented measures: age, grade, K27M, TERTp, IDH, and FGFR1 status)

\begin{tabular}{llllll}
\hline & Coeff & OR (exp [coeff]) & SE (coeff) & Z & p \\
\hline Age & 0.003 & 1.003 & 0.013 & 0.234 \\
\hline Grade & -0.191 & 0.826 & 0.288 & -0.667 \\
\hline H3K27M & -0.159 & 0.853 & 0.484 & -0.329 \\
\hline TERTp & 1.367 & 3.926 & 0.347 & 3.936 \\
\hline IDH & -1.756 & 0.173 & 0.652 & -2.693 \\
\hline FGFR1 & -2.117 & 0.120 & 0.799 & -2.649 \\
\hline
\end{tabular}

N546 and K656 mutations were previously reported in several other cancer types, ${ }^{36,38}$ comprising a wide range of CNS tumors: rosette-forming glioneuronal tumors, ${ }^{39}$ dysembryoplastic neuroepithelial tumors, ${ }^{40}$ pilocytic astrocytomas, ${ }^{41,42}$ diffuse leptomeningeal tumor with glial and neuronal markers, ${ }^{43}$ and pediatric thalamic gliomas. ${ }^{3,18,19,43}$ These studies analyzed isolated cases or small cohorts, which made difficult the assessment of the incidence of FGFR1 mutations in this population. FGFR1 N546 and K656 mutants lead to constitutive activation of FGFR1 tyrosine kinase and downstream RAS-MAPK signaling, contributing to transformation, ${ }^{44}$ and can be targeted by a number of oral highly specific FGFR inhibitors, currently under clinical evaluation, ${ }^{16}$ such as BGJ398, AZD4547, JNJ-42756493, and TAS-120 (a novel irreversible FGFR inhibitor that demonstrated potent activity against N546K mutants), ${ }^{45}$ opening new therapeutic opportunities in this population. BRAF V600E is another actionable target, which has been rarely associated with $\mathrm{H} 3 \mathrm{~K} 27 \mathrm{M}$ in pediatric gangliogliomas and diffuse midline gliomas., ${ }^{76-48}$ However, we did not find any BRAF V600 mutation in all the 68 sequenced patients.

Our study was restricted by the scarcity of available tumor material limiting both histopathologic and genomic analyses. Therefore, our genomic analyses, when possible, were restricted to a panel of selected molecular alterations, while several samples were exhausted at the time of this retrospective analysis. However, the majority of the patients could be assessed for TERT promoter status, which was not covered by previous whole-exome sequencing studies or was technically limited in whole-genome sequencing studies by the very low coverage due to the high GC content of the TERT promoter region. ${ }^{4,19}$ As observed in adult supratentorial glioblastomas, TERTp mutation, which affected $37 \%$ of our patients, was associated with older age, grade IV, poor survival, EGFR amplifications, loss of chromosome 10, and deletion of CDKN2A. Survival of these patients was particularly poor (OS 9.1 months vs 24.2 months for patients without TERTp mutations), even compared to adult patients with hemispheric glioblastomas followed in our institution (OS 13.5 months ${ }^{49}$ ), which may be related to the inability to resect these tumors. TERT promoter appears therefore a prognosticator biomarker of poor survival in patients with adult MLG.

Our findings reinforce the need for histologic confirmation and molecular analyses in adult patients with MLG, given the significant heterogeneity among midline tumors and the presence of recurrent potentially targetable molecular alterations in these often-fatal diseases. While IDH1 and TERT promoter mutations may assist treatment stratification in adult patients with MLG, we show here that histone $\mathrm{H} 3$ mutations do not confer worse prognosis in adult patients with MLG. Our finding of frequent and potentially targetable FGFR1 mutations has important clinical implications in the current context of anti-FGFR trials, and further reinforces the need for molecular analyses. In this population characterized by a risk for biopsies, the development of liquid biopsy allowing a noninvasive assessment of these few mutational hotspots therefore would be particularly relevant.

\section{Author contributions}

A.P., A.L.D.S., and M.S. designed the study. A.P., M.T., A.L.D. S., and M.S. wrote the manuscript. G.B., E.T., S.M., and Y.S. performed the gene analysis. F.B. performed the histologic analysis and immunohistochemistry. A.P. and J.S. analyzed the MRI. Clinical data were collected and analyzed by A.P., M. S., and A.L.D.S. All authors contributed to the data analysis and interpretation and read and approved the manuscript.

\section{Acknowledgment}

The authors thank Anne-Marie Lekieffre, Muriel Brandel, Armelle Rametti, Ines Detrait, and Amithys Rahimian for database management and technical support.

\section{Study funding}

Supported by the Institut National du Cancer (INCa; PRTK15-061), the Ligue Nationale Contre le Cancer, Comité de Paris, and the "Princesse Margot" association. A.L.D.S. received support from "Premio Riquier" and a donation in the memory of Olivier Ribes.

\section{Disclosure}

The authors report no disclosures relevant to the manuscript. Go to Neurology.org/N for full disclosures. 


\section{References}

1. Ostrom QT, Gittleman H, Fulop J, et al. CBTRUS statistical report: primary brain and central nervous system tumors diagnosed in the United States in 2008-2012. NeuroOncol 2015; 17(suppl 4):iv1-iv62.

2. Buczkowicz P, Bartels U, Bouffet E, Becher O, Hawkins C. Histopathological spectrum of paediatric diffuse intrinsic pontine glioma: diagnostic and therapeutic implications. Acta Neuropathol 2014;128:573-581.

3. Schwartzentruber J, Korshunov A, Liu XY, et al. Driver mutations in histone H3.3 and chromatin remodelling genes in paediatric glioblastoma. Nature 2012;482:226-231.

4. Wu G, Broniscer A, McEachron TA, et al. Somatic histone $\mathrm{H} 3$ alterations in pediatric diffuse intrinsic pontine gliomas and non-brainstem glioblastomas. Nat Genet 2012; 44:251-253.

5. Castel D, Philippe C, Calmon R, et al. Histone H3F3A and HIST1H3B K27M mutations define two subgroups of diffuse intrinsic pontine gliomas with different prognosis and phenotypes. Acta Neuropathol 2015;130:815-827.

6. Khuong-Quang DA, Buczkowicz P, Rakopoulos P, et al. K27M mutation in histone H3.3 defines clinically and biologically distinct subgroups of pediatric diffuse intrinsic pontine gliomas. Acta Neuropathol 2012;124:439-447.

7. Solomon DA, Wood MD, Tihan T, et al. Diffuse midline gliomas with histone H3K27M mutation: a series of 47 cases assessing the spectrum of morphologic variation and associated genetic alterations. Brain Pathol 2016;26:569-580.

8. Sturm D, Witt H, Hovestadt V, et al. Hotspot mutations in H3F3A and IDH1 define distinct epigenetic and biological subgroups of glioblastoma. Cancer Cell 2012;22:425-437.

9. Bjerke L, Mackay A, Nandhabalan M, et al. Histone H3.3 mutations drive pediatric glioblastoma through upregulation of MYCN. Cancer Discov 2013;3:512-519.

10. Louis DN, Perry A, Reifenberger G, et al. The 2016 World Health Organization classification of tumors of the central nervous system: a summary. Acta Neuropathol 2016;131:803-820.

11. Larjavaara S, Mäntylä R, Salminen T, et al. Incidence of gliomas by anatomic location. Neuro-Oncol 2007;9:319-325.

12. Aihara K, Mukasa A, Gotoh K, et al. H3F3A K27M mutations in thalamic gliomas from young adult patients. Neuro-Oncol 2014;16:140-146.

13. Feng J, Hao S, Pan C, et al. The H3. 3 K27M mutation results in a poorer prognosis in brainstem gliomas than thalamic gliomas in adults. Hum Pathol 2015;46:1626-1632.

14. Meyronet D, Esteban-Mader M, Bonnet C, et al. Characteristics of H3 K27M-mutant gliomas in adults. Neuro-Oncol 2017;19:1127-1134.

15. Reyes-Botero G, Giry M, Mokhtari K, et al. Molecular analysis of diffuse intrinsic brainstem gliomas in adults. J Neurooncol 2014;116:405-411.

16. Touat M, Ileana E, Postel-Vinay S, André F, Soria JC. Targeting FGFR signaling in cancer. Clin Cancer Res 2015;21:2684-2694.

17. Mondesir J, Willekens $\mathrm{C}$, Touat $\mathrm{M}$, de Botton S. IDH1 and IDH2 mutations as novel therapeutic targets: current perspectives. J Blood Med 2016;7:171-180.

18. Ryall S, Krishnatry R, Arnoldo A, et al. Targeted detection of genetic alterations reveal the prognostic impact of $\mathrm{H} 3 \mathrm{~K} 27 \mathrm{M}$ and MAPK pathway aberrations in paediatric thalamic glioma. Acta Neuropathol Commun 2016;4:93.

19. Zhang L, Chen LH, Wan $\mathrm{H}$, et al. Exome sequencing identifies somatic gain-offunction PPM1D mutations in brainstem gliomas. Nat Genet 2014;46:726-730.

20. Reyes-Botero G, Mokhtari K, Martin-Duverneuil N, Delattre JY, Laigle-Donadey F. Adult brainstem gliomas. Oncologist 2012;17:388-397.

21. VASARI Research Project: the Cancer Imaging Archive (TCIA) Public Access: Cancer Imaging Archive Wiki [online]. Available at: wiki.cancerimagingarchive.net/ display/Public/VASARI+Research+Project. Accessed January 24, 2018.

22. Labussière M, Boisselier B, Mokhtari K, et al. Combined analysis of TERT, EGFR, and IDH status defines distinct prognostic glioblastoma classes. Neurology 2014;83: 1200-1206.

23. Labussière M, Rahimian A, Giry M, et al. Chromosome 17p Homodisomy is associated with better outcome in $1 \mathrm{p} 19 \mathrm{q}$ non-codeleted and IDH-mutated gliomas. Oncologist 2016;21:1131-1135.

24. Bielle F, Ducray F, Mokhtari K, et al. Tumor cells with neuronal intermediate progenitor features define a subgroup of $1 \mathrm{p} / 19 \mathrm{q}$ co-deleted anaplastic gliomas. Brain Pathol 2017;27:567-579.
25. Reuss DE, Sahm F, Schrimpf D, et al. ATRX and IDH1-R132H immunohistochemistry with subsequent copy number analysis and IDH sequencing as a basis for an "integrated" diagnostic approach for adult astrocytoma, oligodendroglioma and glioblastoma. Acta Neuropathol 2015;129:133-146.

26. Capper D, Weissert S, Balss J, et al. Characterization of $\mathrm{R} 132 \mathrm{H}$ mutation-specific IDH1 antibody binding in brain tumors. Brain Pathol 2010;20:245-254.

27. Venneti S, Santi M, Felicella MM, et al. A sensitive and specific histopathologic prognostic marker for H3F3A K27M mutant pediatric glioblastomas. Acta Neuropathol 2014;128:743-753.

28. Cancer Genome Atlas Research Network. Comprehensive genomic characterization defines human glioblastoma genes and core pathways. Nature 2008;455:1061-1068.

29. Ceccarelli M, Barthel FP, Malta TM, et al. Molecular profiling reveals biologically discrete subsets and pathways of progression in diffuse glioma. Cell 2016;164:550-563.

30. Lamborn KR, Chang SM, Prados MD. Prognostic factors for survival of patients with glioblastoma: recursive partitioning analysis. Neuro-Oncol 2004;6:227-235.

31. Pignatti F, van den Bent M, Curran D, et al. Prognostic factors for survival in adult patients with cerebral low-grade glioma. J Clin Oncol 2002;20:2076-2084.

32. Wong ET, Hess KR, Gleason MJ, et al. Outcomes and prognostic factors in recurrent glioma patients enrolled onto phase II clinical trials. J Clin Oncol 1999;17:2572-2578.

33. Gessi M, Gielen GH, Dreschmann V, Waha A, Pietsch T. High frequency of H3F3A K27M mutations characterizes pediatric and adult high-grade gliomas of the spinal cord. Acta Neuropathol 2015;130:435-437.

34. Korshunov A, Capper D, Reuss D, et al. Histologically distinct neuroepithelial tumors with histone 3 G34 mutation are molecularly similar and comprise a single nosologic entity. Acta Neuropathol 2016;131:137-146.

35. Theeler BJ, Ellezam B, Melguizo-Gavilanes I, et al. Adult brainstem gliomas: correlation of clinical and molecular features. J Neurol Sci 2015;353:92-97.

36. Salmaggi A, Fariselli L, Milanesi I, et al. Natural history and management of brainstem gliomas in adults: a retrospective Italian study. J Neurol 2008;255:171-177.

37. Mellinghoff IK, Touat M, Maher E, et al. ACTR-46. AG120, a first-in-class mutant IDH1 inhibitor in patients with recurrent or progressive IDH1 mutant glioma: results from the phase 1 glioma expansion cohorts. Neuro-Oncol 2016;18:vi12.

38. Babina IS, Turner NC. Advances and challenges in targeting FGFR signalling in cancer. Nat Rev Cancer 2017;17:318-332.

39. Gessi M, Moneim YA, Hammes J, et al. FGFR1 mutations in rosette-forming glioneuronal tumors of the fourth ventricle. J Neuropathol Exp Neurol 2014;73:580-584.

40. Rivera B, Gayden T, Carrot-Zhang J, et al. Germline and somatic FGFR1 abnormalities in dysembryoplastic neuroepithelial tumors. Acta Neuropathol 2016;131:847-863.

41. Becker AP, Scapulatempo-Neto C, Carloni AC, et al. KIAA1549: BRAF gene fusion and FGFR1 hotspot mutations are prognostic factors in pilocytic astrocytomas. J Neuropathol Exp Neurol 2015;74:743-754.

42. Jones DTW, Hutter B, Jäger N, et al. Recurrent somatic alterations of FGFR1 and NTRK2 in pilocytic astrocytoma. Nat Genet 2013;45:927-932.

43. Dyson K, Rivera-Zengotita M, Kresak J, et al. FGFR1 N546K and H3F3A K27M mutations in a diffuse leptomeningeal tumour with glial and neuronal markers. Histopathology 2016;69:704-707.

44. Bennett JT, Tan TY, Alcantara D, et al. Mosaic activating mutations in FGFR1 cause encephalocraniocutaneous lipomatosis. Am J Hum Genet 2016;98:579-587.

45. Ochiiwa H, Fujita $\mathrm{H}$, Itoh $\mathrm{K}$, et al. Abstract A270: TAS-120, a highly potent and selective irreversible FGFR inhibitor, is effective in tumors harboring various FGFR gene abnormalities. Mol Cancer Ther 2013;12:A270.

46. Joyon N, Tauziède-Espariat A, Alentorn A, et al. K27M mutation in H3F3A in ganglioglioma grade I with spontaneous malignant transformation extends the histopathological spectrum of the histone $\mathrm{H} 3$ oncogenic pathway. Neuropathol Appl Neurobiol 2017;43:271-276.

47. Nguyen AT, Colin C, Nanni-Metellus I, et al. Evidence for BRAF V600E and H3F3A $\mathrm{K} 27 \mathrm{M}$ double mutations in paediatric glial and glioneuronal tumours. Neuropathol Appl Neurobiol 2015;41:403-408.

48. Pagès $\mathrm{M}$, Beccaria $\mathrm{K}$, Boddaert $\mathrm{N}$, et al. Co-occurrence of histone $\mathrm{H} 3 \mathrm{~K} 27 \mathrm{M}$ and BRAF V600E mutations in paediatric midline grade I ganglioglioma. Brain Pathol 2018;28:103-111.

49. Nencha U, Rahimian A, Giry M, et al. TERT promoter mutations and rs 2853669 polymorphism: prognostic impact and interactions with common alterations in glioblastomas. J Neurooncol 2016;126:441-446. 